\title{
Range Extender Vehicle Concept Based on High Temperature Polymer Electrolyte Membrane Fuel Cell
}

\author{
Dave Dickinson \\ German Aerospace Center (DLR) \\ Institute of Vehicle Concepts \\ Pfaffenwaldring 38-40 \\ 70569 Stuttgart, Germany \\ Email : dave.dickinson@dlr.de
}

\author{
Mounir Nasri \\ German Aerospace Center (DLR) \\ Institute of Vehicle Concepts \\ Pfaffenwaldring 38-40 \\ 70569 Stuttgart, Germany \\ Email: mounir.nasri@dlr.de
}

\begin{abstract}
Battery electric vehicles that would be suitable for urban traffic as well as for longer distances will be equipped with a range extender (REX). In this range extender vehicle concept, the powertrain is driven mainly by the high performance li-ion battery added by a HT-PEFC (Polymer Electrolyte Membrane Fuel Cell). The on-board fuel cell range extender serves as an additional energy source, which charges the high performance battery during the trip especially in a long distance trip.

On the basis of existing system models, such as fuel cell and battery, a complete vehicle model is been developed with the help of the AlternativeVehicles library [1], especially the thermal model has been extended and parameterized. For the thermal coupling between the high-temperature fuel cell and the hydrogen storage, a high temperature cooling circuit is modeled. The battery temperature control is represented in the model by means of a low-temperature cooling circuit. Considered the challenges that are now placed on modern cars, several scenarios such as cold start and warm-up phase are been created. For these scenarios, suitable operating strategies can be developed and integrated into the overall vehicle model. Based on various driving cycles, the thermal and electrical behavior of the overall system is investigated.
\end{abstract}

Keywords-High temperature fuel cells; on-board recharge; range extender; alternative drive concept; hybrid electric vehicle; total vehicle simulation.

\section{INTRODUCTION}

To achieve the set by the European Commission emission reduction of $60 \%$ compared to 1990 in the transport sector, alternative drive concepts with lower emission are required. According to the European Commission's Paper on Transport 2011, the proportion of the conventional operated fuels cars should be halved and reduced in cities by 2050 to zero [2].

A promising solution is a battery electric range extender (REX) vehicle, which is suitable for urban traffics as well as for longer distances, in which a high temperature polymer electrolyte membrane fuel cell (HT-
PEFC) is integrated as a REX unit (figure 1). This is an attractive way, which combines both technologies (li-ion battery and fuel cell) either permanently or on demand and also promotes the introduction of e-mobility as a sustainable traffic concept.

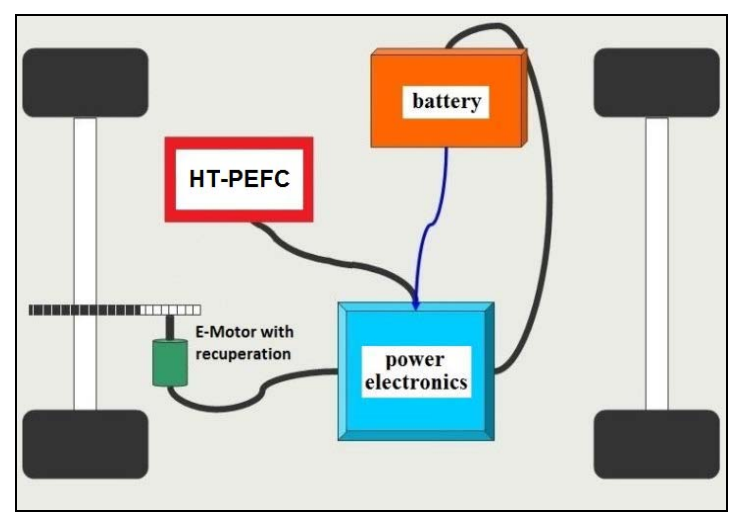

Fig. 1: Architecture of the high temperature fuel cell range extender vehicle

On the basis of existing system models the range extender powertrain is modeled and the matching thermal management concept using the own DLRAlternativeVehicles modelica library [1] is developed.

To determine the thermal and electrical requirements of different driving cycles for the entire system, the powertrain of an existing test vehicle called HyLite [3] is been replaced by the smart electric drive vehicle model. The technical data of the modeled vehicle are summarized in table 1.

\begin{tabular}{|c|c|}
\hline Parameter & Value \\
\hline Curb weight & $840 \mathrm{~kg}$ \\
\hline Battery mass & $175 \mathrm{~kg}$ \\
\hline $\begin{array}{c}\text { Loading weight (fuel cell system, } \\
\text { hydrogen tank and periphery) }\end{array}$ & $140 \mathrm{~kg}$ \\
\hline
\end{tabular}




\begin{tabular}{|c|c|}
\hline Maximum engine performance & $55 \mathrm{~kW}$ \\
\hline $\begin{array}{c}\text { Driving resistance }(\mathrm{ABC}- \\
\text { Coefficient })\end{array}$ & $\begin{array}{c}{[\mathrm{A}=77.88 ; \mathrm{B}=1.222 ;} \\
\mathrm{C}=0.4475]\end{array}$ \\
\hline Drag $\mathrm{c}_{\mathrm{W}}$ & $0,36 \mathrm{~m}^{2}$ \\
\hline Frontal area $\mathrm{A}$ & $2,08 \mathrm{~m}$ \\
\hline
\end{tabular}

Table 1: Vehicle data used for the model parameterization

\section{OVERCOME COMMUTER ROUTE AND COMPARISON OF BOTH TECHNOLOGIES}

In the figure 2 the typical commuting distances from home to work in Germany are shown and these values can be up to about $50 \mathrm{~km} \mathrm{[4].}$

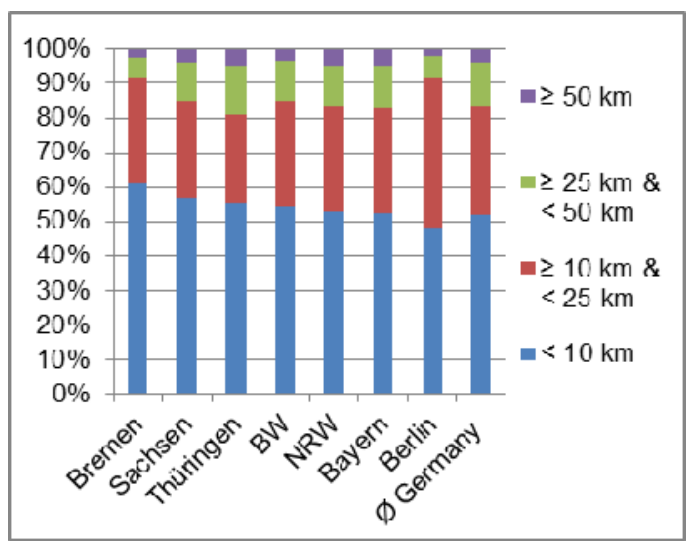

Fig. 2: Commuting distance in Germany

In this paper, a real commuter route between the cities Stuttgart-Lampoldshausen-Stuttgart (Germany) is used, which is driven over the rural road. The velocity profile, which is recorded by means of a mobile GPS device in a real trip, is shown in the figure 3. The outward and return journey lasted without intermission about 3 hours 15 minutes. The total distance is approximately $192 \mathrm{~km}$ and the height difference is about $350 \mathrm{~m}$.
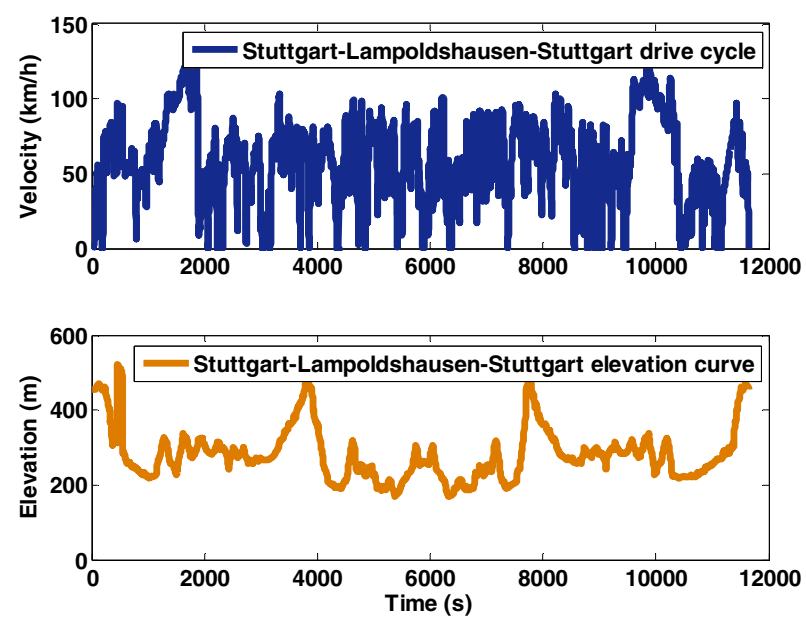

Fig. 3: Stuttgart-Lampoldshausen-Stuttgart drive cycle
The first aim of this publication is to overcome this round trip without refueling using the described battery electric vehicle high temperature fuel cell (HT-PEFC) REX. The second objective is to increase the efficiency of the battery in a low ambient temperature on an effective utilization of the thermal coupling between the battery and the HT-PEFC.

To know the basic idea of a REX-vehicle closer according to the trend of both technologies, the Li-ion battery system and the HT-PEFC system will be compared. The comparison is focused on the energy density and based on the basis of available products in the market. In the comparison, it includes the volume and weight of the HT-PEFC-tank, however without the observance of the peripheries. In the same case, the battery's peripheries were not considered. In figure 4 , the gravimetric energy densities from both are shown.

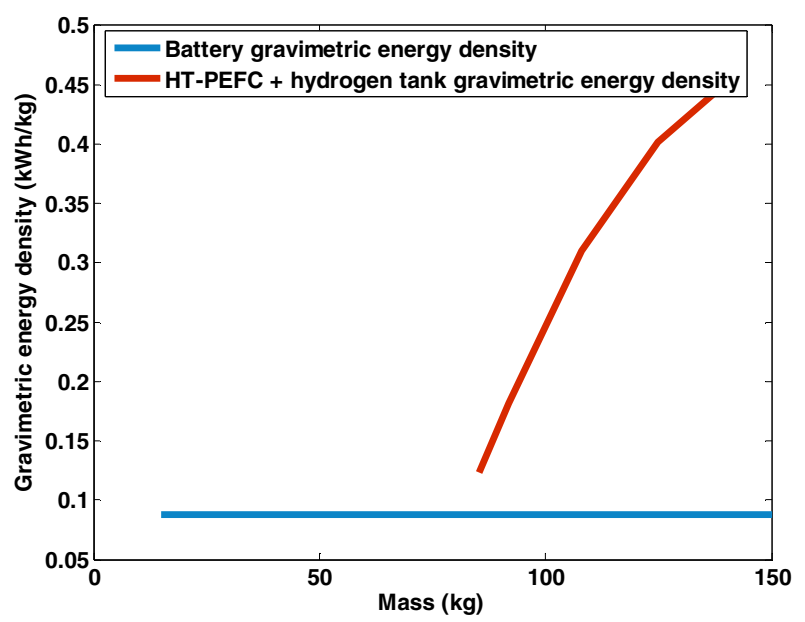

Fig. 4: Comparison of the gravimetric energy density

It is clear that the HT-PEFC has a clear advantage in comparison to the battery. In figure 5 the volumetric energy densities are displayed.

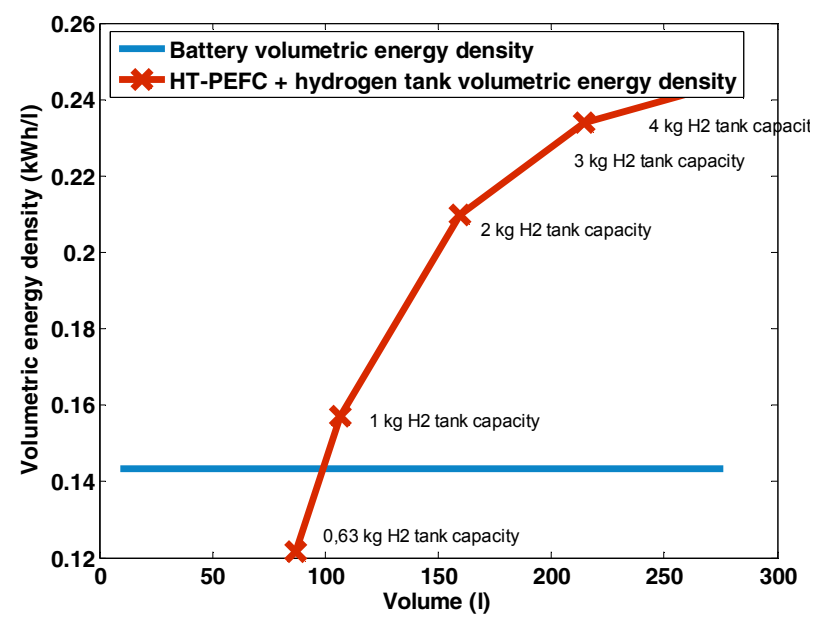

Fig. 5: Comparison of the volumetric energy density 
Here is also seen: from a certain tank storage capacity of the HT-PEFC (over about $0.9 \mathrm{~kg}$ ), the HT-PEFC system has a higher volumetric energy density compared to the Li-ion battery system. However the fuel cell technologies are nowadays still immature, which affect a poor cost effectiveness of the system including the peripheral equipment.

As been clarified, the background of this idea is therefore to take a benefit of the gravimetric and volumetric energy density of the fuel cell system to extend the range of electric vehicles and combine it with the advantageous dynamic performance of the battery. Additional advantage of this idea is to use the waste heat of the HT-PEFC for tempering the battery and possibly to warm the vehicle cabin.

\section{IMPORTANT COMPONENTS OF THE RANGE EXTENDER POWERTRAIN}

\section{A. Fuel Cell System}

The high temperature fuel cell system consist of 120 cells. The cells are connected in series with each other. The maximum power is $6 \mathrm{~kW}$. The schematic structure of the HT-PEFC is shown in the figure 6. The hydrogen capacity of the tank is about $0.905 \mathrm{~kg}$.

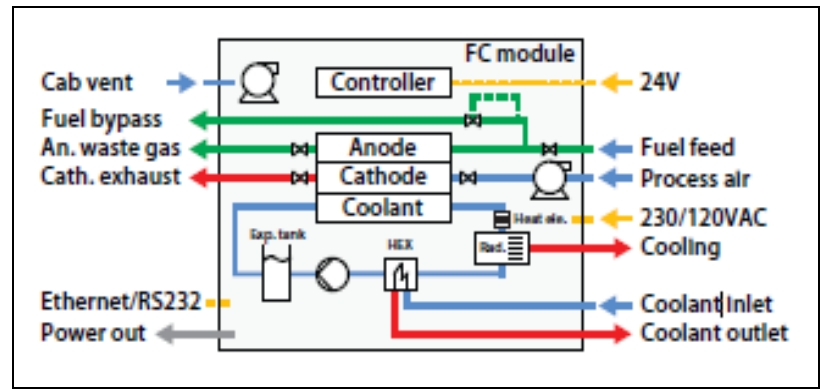

Fig. 6: Schematic structure of the HT-PEFC

For the modelling of the fuel cell a map-based model is used [5]. This model is suitable for system simulation [1], in which a high computation speed is required. The polarization curve is taken from measurements and data sheets. The validation is done by a comparison between the simulation results and the manufacturer's measurement results. For the thermal simulation the setting of the thermal mass is very important, since the power loss leads to a change of the temperature of the thermal mass. The thermal dissipation of the fuel cell is proportional to the voltage difference from open circuit voltage $\left(\mathrm{U}_{0}\right)$ and the actual voltage $\left(\mathrm{U}_{\text {Stack }}\right)[6]$ and is calculated as follows:

$$
P_{\text {loss }}=\left(N * U_{0}-U_{\text {stack }}\right) * I
$$

With $N$ is the number of cells, $U_{0}=1.23 \mathrm{~V}$ and $I$ is the battery current.

\section{B. Battery}

Serial to the fuel cell system the batteries are connected. A series 3 parallel of 31 Li-ion-battery-cells have been established. The final charge voltage of the cell is $4.0 \mathrm{~V}$; the maximum charge voltage is at $391 \mathrm{~V}$. the maximum discharge rate can be up to a maximum of $200 \mathrm{~A}$. The net energy capacity at room temperature is $17.6 \mathrm{kWh}$.

The AV library provides two different available battery models, map-based and impedance-based model [7]. The map-based battery model is been used here for the modeling of single cells. With the help of the maps from data sheets, the appropriate values for the internal resistance and open-circuit voltage can be specified as a function of state of charge, current and temperature [8].

\section{Thermal Circuit}

The cooling system for the range extender drivetrain consists of a high-temperature and low-temperature cooling circuit and is implemented in the simulation environment Dymola. The high-temperature cooling circuit represents the thermal cycle of the fuel cell system and consists of the HT-PEFC, pump, hightemperature radiator and the associated lines (figure 7).

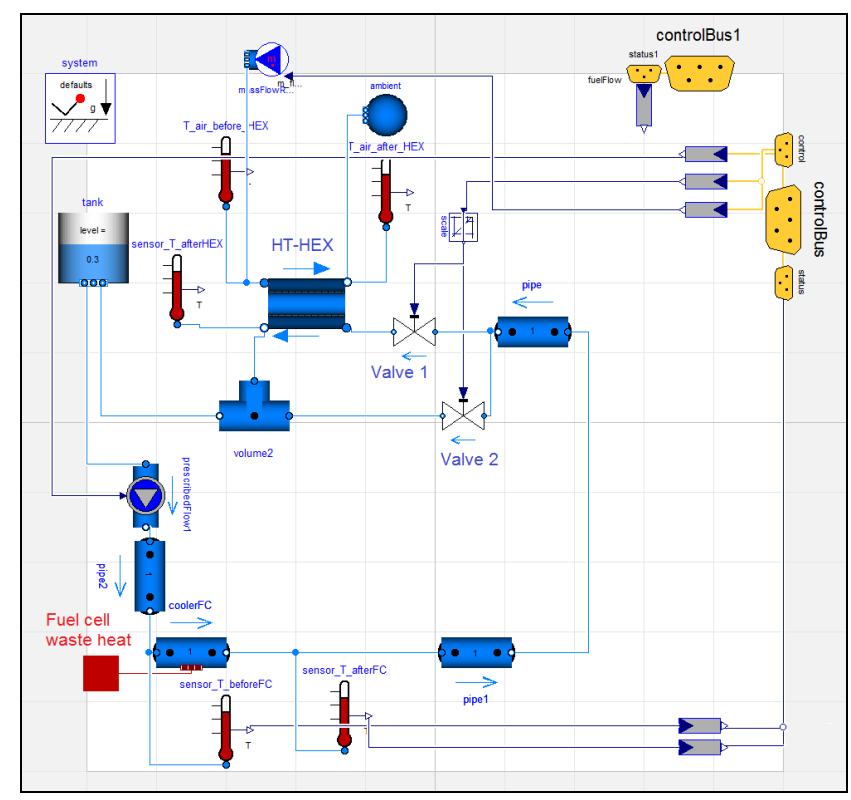

Fig. 7: The high-temperature cooling circuit

The working temperatures of the HT-PEFC are between $100-160{ }^{\circ} \mathrm{C}$. As a coolant, TEG (Triethylene Glycol) is been used. TEG is a member of a homologous series of dihydroxy alcohols. It is a colorless, odorless and stable liquid with high viscosity and a high boiling 
point and especially for the use of operating temperatures between $+100{ }^{\circ} \mathrm{C}$ and $+285^{\circ} \mathrm{C}$.

The tempering of the battery is represented in the model by means of a low-temperature cooling circuit with the coolant mixture of water-glycol. For performance and durability reasons, the battery should be operated only in a certain temperature window: From operating temperatures of $50{ }^{\circ} \mathrm{C}$, the battery life is reduced and a loss of efficiency is observed. At very low temperatures, below about $10^{\circ} \mathrm{C}$, the performance and the efficiency of the battery decrease also significantly.

As can be seen in figure 8 , the battery circuit, the electrical components, the battery and the electric machine (EM), are connected with a low-temperature cooler (LT-HEX), which transfers the excess heat loss to the environment. The valves (valve 1,2 and 3) are used depending on the current operating state for the supply and to shut down some cooling circuit branches: If rapid heating of the battery is required in the absence of engine heat, only the valve 2 is opened. To dissipate the heat of the battery, only the valve 1 will be opened.

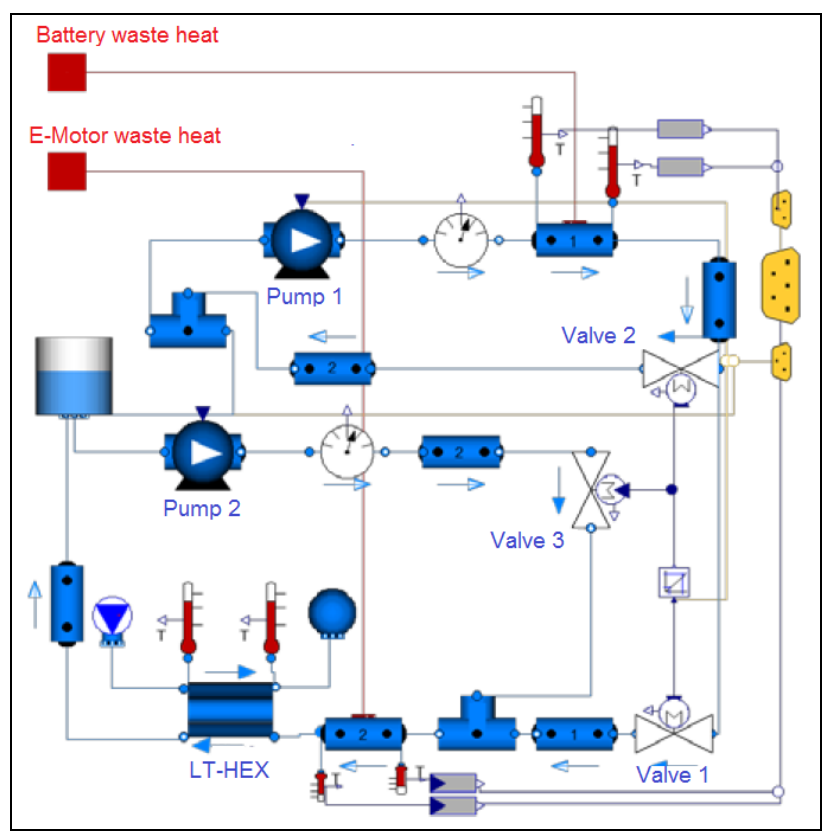

Fig. 8: The low-temperature cooling circuit

Figure 9 shows the overall vehicle model, which includes 5 main subsystem namely the powertrain model, the thermal model, the controller module, the drive cycle (driver model) and the boundary conditions model.

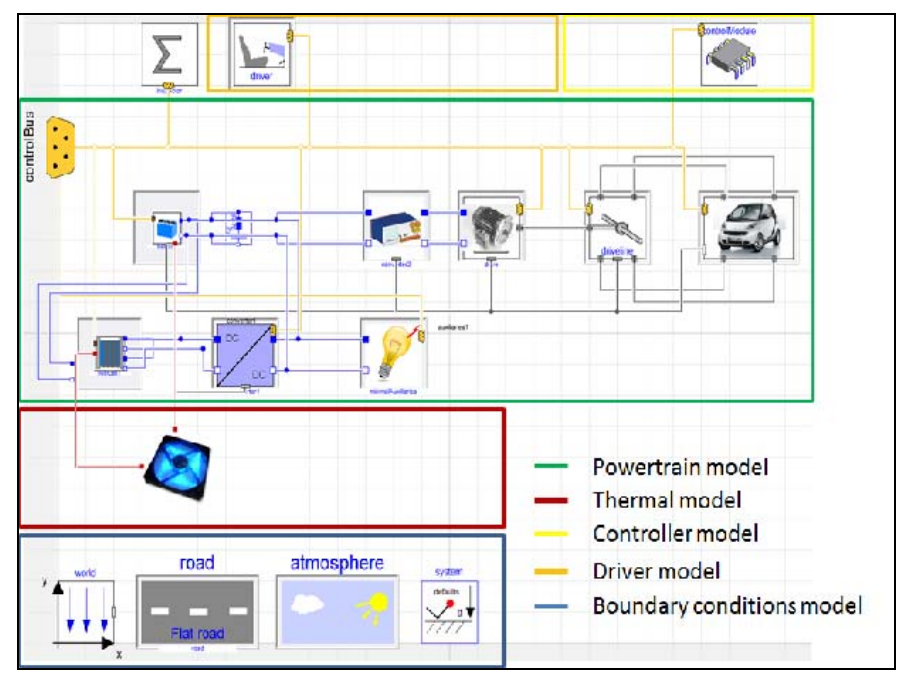

Fig. 9: The overall vehicle model implemented in Dymola/Modelica

\section{OPERATING StRATEgIES}

For the following thermal scenarios, especially cold start, high operating temperatures and operation strategies will be developed.

\section{A. Cold Start}

The following figure 10 shows the temperature progress of both main elements during a cold start at a minus $10^{\circ} \mathrm{C}$ ambient temperature for a sample short drive of Stuttgart-Lampoldshausen drive cycle. In this sample trip, the HT-PEFC is been preheated nearly at the beginning of the trip. As the temperature of the HT-PEFC reaches $100{ }^{\circ} \mathrm{C}$, it begins to work and produces heat; therefore the temperature increases significantly afterward (figure 10).

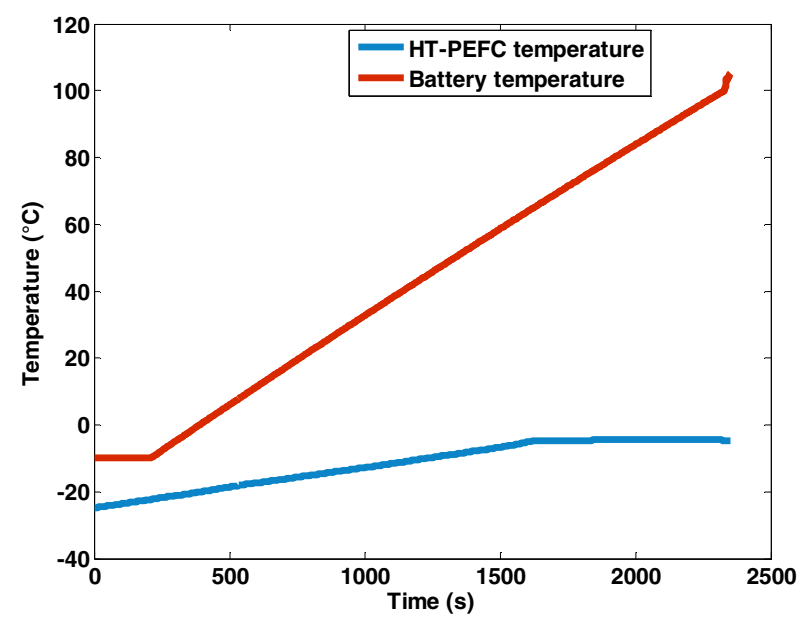

Fig. 10: HT-PEFC and battery temperature progress during the trip Stuttgart-Lampoldshausen

As can be seen in figure 10, it takes about 35 minutes until the fuel cell reaches an operating temperature of 
about $100^{\circ} \mathrm{C}$ by heating it up with a $600 \mathrm{~W}$ PTC heater. The preheating time depends on some parameters; in this case the fuel cell stack has a mass of $22 \mathrm{~kg}$ and a thermal capacity of $450 \mathrm{~J} / \mathrm{kg} \mathrm{K}$.

To improve the efficiency of the battery at low temperatures, a $2.7 \mathrm{~kW}$ PTC heater has been implemented in the battery model. The PTC heater heats the battery up to $10{ }^{\circ} \mathrm{C}$ and then is been switched off automatically.

\section{B. Operating Phase}

The main task during the warm-phase operation is to keep the temperature of the fuel cell within the recommended operating temperature range. So that the upper limit temperature $165^{\circ} \mathrm{C}$ is not exceeded, the thermostat (valve 1 in Figure 2) opens at $160^{\circ} \mathrm{C}$.

The high-temperature radiator is included with the circulation and issued the excess heat to the outside air. Alternatively, this heat can also be used for heating the interior. The air mass flow through the high-temperature radiator is controlled so that the refrigerant inlet temperature of the fuel cell is around $160{ }^{\circ} \mathrm{C}$. The performance of the battery and the HT-PEFC at the operating phase during a sample trip of StuttgartLampoldshausen is been shown in figure 11. The HTPEFC is been preheated at the first 2400 seconds and then been turned on afterwards (at a long distance trip) till the hydrogen tank is been depleted. The continuous net power to charge the battery during a long distance trip is $5 \mathrm{~kW}$.

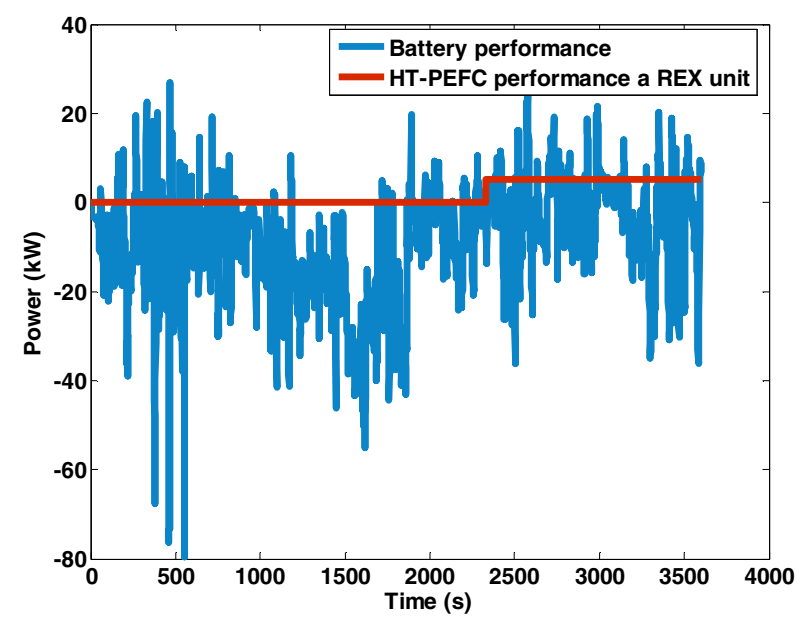

Fig. 11: Battery and HT-PEFC performance during an operating phase

\section{VARIANTS CALCULATION OF THE OVERALL SYSTEM}

At first, an electric vehicle without a REX unit was simulated to overcome the previously introduced commuter route (figure 3 ). The figure 12 shows the result of the first simulation. The ambient temperature here is minus $10{ }^{\circ} \mathrm{C}$. The average speed is $60.5 \mathrm{~km} / \mathrm{h}$ and can be up to $123 \mathrm{~km} / \mathrm{h}$. These two boundary conditions (low ambient temperature and quite high driving speed) degrade the reliability of the battery and thereby decrease the current carrying capacity. Therefore, the simulation was interrupted after $7800 \mathrm{~s}$ (about 2 hours trip), as also the $\mathrm{SoC}$ was already close to zero.
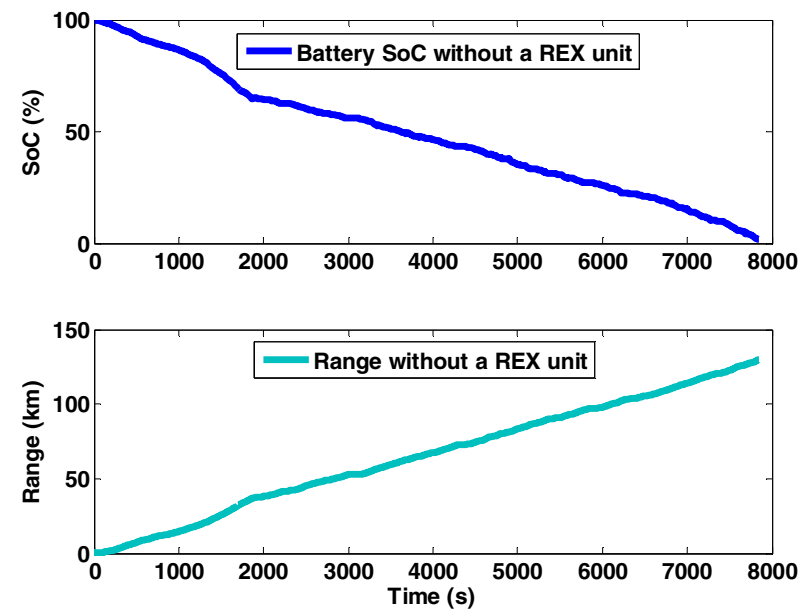

Fig. 12: Battery's SoC progression and electric vehicle range without a REX unit

In the second simulation, the HT-PEFC was installed into the overall vehicle simulation as a REX unit. The same result parameters as the first simulation are shown in figure 13. To draw a precise comparison, the exact boundary conditions as well as in the first simulation, were used. The electric car now can manage to overcome the commuter route and the simulation runs until the desired goal.
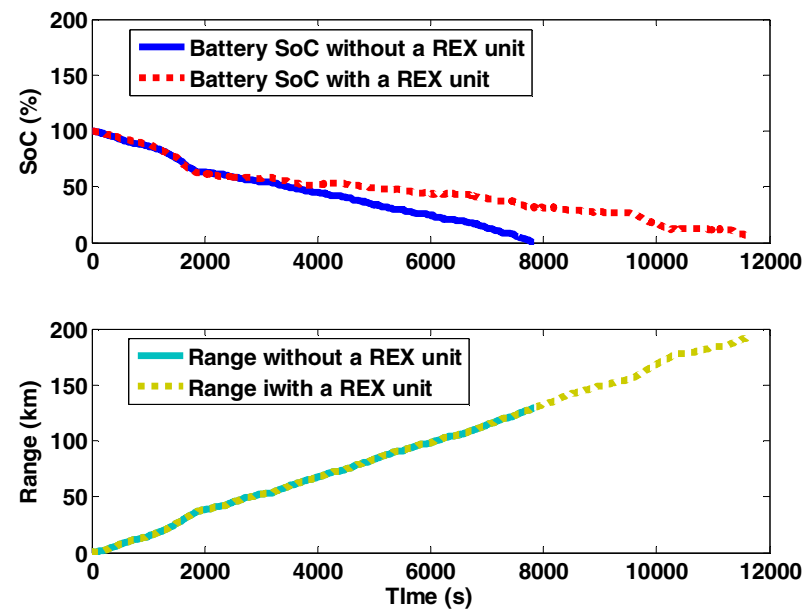

Fig. 13: Battery's SoC progression and electric vehicle range with a REX unit

In the final simulation, the overall model of the second simulation was supplemented additionally with the thermal coupling between the battery and HT-PEFC, 
which has already been presented in the Chapter III. After the PTC heater heated the battery up to $10^{\circ} \mathrm{C}$, additionally a thermal coupling took a progress in the simulation, which leads the loss heat from the fuel cell into the vehicle cooling circuit. As a result, the battery was further heated up to its optimum operating temperature, about $40-50{ }^{\circ} \mathrm{C}$ (figure 14). As can be seen, the temperature of the fuel cell is also maintained in the manufacturer's recommended operating range, between $100-160^{\circ} \mathrm{C}$.

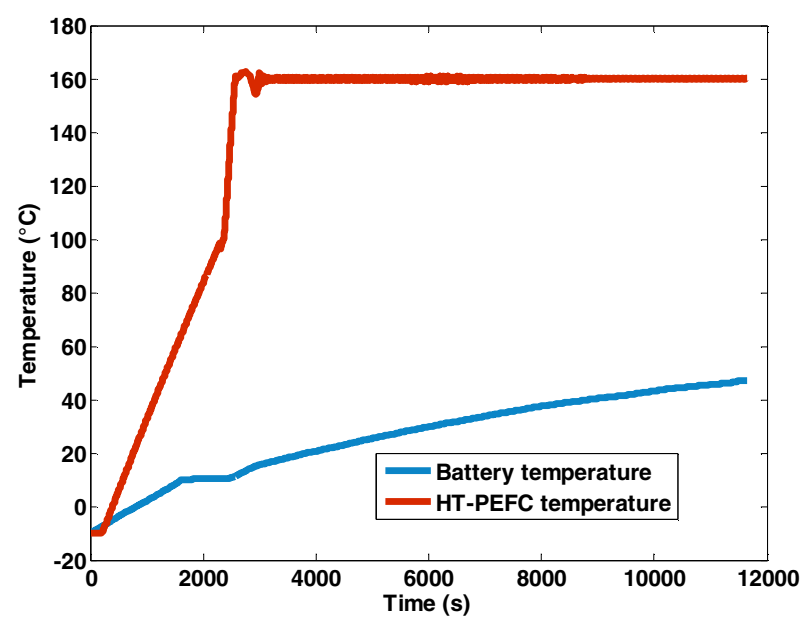

Fig. 14: Temperatures of the battery and the HT-PEFC during a trip of Stuttgart-Lampoldshausen-Stuttgart

To see the extra effect of this strategy more accurately, the SoC and heat losses of the battery from the second and third simulation were represented and compared in figure 15. It turns out that there is an improvement in the efficiency of the battery at the third simulation.
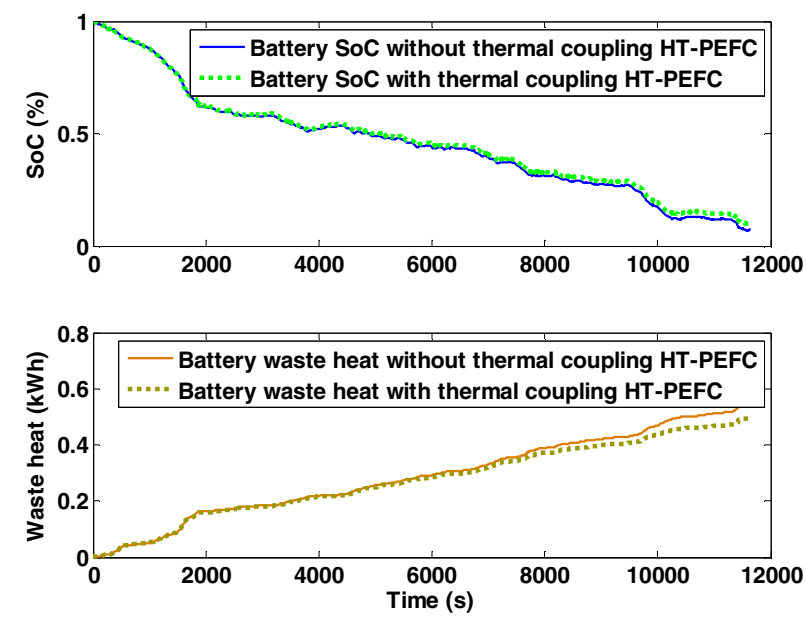

Fig. 15: SoC and the heat loss of the battery with and without a thermal coupling to the HT-PEFC

\section{CONCLUSION}

With the DLR-AlternativeVehicles modelica library [1] a complete range extender (REX) powertrain was modeled using a high temperature fuel cell and thermal circuit, which are integrated into the total vehicle model. With the generated model various scenarios were investigated, such as driving of an electric vehicle with and without Range Extender unit, the behavior of the thermal cycle and the benefit impact of the thermal coupling between the high temperature fuel cell and the li-ion battery.

The thermal and electrical overall system behavior was examined during a trip of a real commute route Stuttgart-Lampoldshausen. It could be shown that it is possible to overcome the commute route with the aid of the construed range extender, meanwhile the original subcompact electric vehicle (smart electric drive) is not capable. Generally the range can be extended up to $38 \%$. Apart from that, the waste heat of the high temperature fuel cell could be forwarded to the vehicle thermal cycle for tempering the battery. As a further benefit, it leads to an increasing of the li-ion battery's discharge efficiency during trip.

The vehicle cabin is been planned as a next step, as to create an interior space model and to integrate into the overall vehicle model. With this overall thermal vehicle model, the further investigations of the energy and thermal management of fuel cell vehicles can be performed and the suitable operating strategies for the heating of the vehicle cabin can be developed. By using an appropriate operating strategy, the average $4.5 \mathrm{~kW}$ of power consumption [9] to heat the subcompact vehicle cabin can possibly completely be covered by the waste heat of the fuel cell.

\section{REFERENCES}

[1] J. Ungethüm, D. Hülsebusch, H. Dittus und T. Braig, Simulation of alternative powertrains in Modelica, ASIM Conference, Ulm, 2010.

[2] EU Commission, Roadmap to a Single European Transport Area - Towards a competitive and resource efficient transport system, Brussels, 28.3.2011.

[3] H. E. Frederick. and P. Treffinger, Hylite technology platform for fuel cell hybrid vehicle, ATZ05, 2006.

[4] U. Winkelmann, "Some commute far - commuters in the states compared," in in the monthly statistical bulletin, BadenWürttemberg, Deutschland, Apr. 2010.

[5] D. Hülsebusch, J. Ungethüm and et al., Multidisciplinary simulation of vehicles, ATZ10, 2009.

[6] D. Wenger, Metal hydride for hydrogen supply and cooling of fuel cell vehicles, dissertation, Technical University of Munich, 2009. 
[7] Z. Jianga, R.A. Dougala and et al., Simulation of a thermally coupled metal-hydride hydro-genstorage and fuel cell system, Journal of Power Sources 142, S. 92-102, 2005.

[8] Dickinson, Dave and Shitole, Manikprasad, Use of a high performance Lithium iron phosphate battery in the fuel cell range extender vehicle concept, Batterietag NRW und Kraftwerk Batterie 2013, 25. Feb. 2013 - 27. Feb.2013, Aachen, Germany.

[9] H. Grossmann, Car air conditioning, Berlin, Heidelberg, Springer Verlag, 2010. 